\title{
Body Girth as an Alternative to Body Mass for Establishing Condition Indexes in Field Studies: A Validation in the King Penguin
}

\author{
Vincent A. Viblanc $c^{1,2, *}$ \\ Pierre Bize ${ }^{1}$ \\ François Criscuolo ${ }^{2}$ \\ Maryline Le Vaillant ${ }^{2}$ \\ Claire Saraux ${ }^{2,3}$ \\ Sylvia Pardonnet ${ }^{2}$ \\ Benoit Gineste $^{2}$ \\ Marion Kauffmann ${ }^{2}$ \\ Onésime Prud'homme ${ }^{2}$ \\ Yves Handrich ${ }^{2}$ \\ Sylvie Massemin ${ }^{2}$ \\ René Groscolas ${ }^{2}$ \\ Jean-Patrice Robin ${ }^{2}$ \\ ${ }^{1}$ Department of Ecology and Evolution, Biophore, University \\ of Lausanne, CH-1015 Lausanne, Switzerland; ${ }^{2}$ Université de \\ Strasbourg, Institut Pluridisciplinaire Hubert Curien, \\ Département Ecologie, Physiologie et Ethologie, 23 rue \\ Becquerel, 67037 Strasbourg, France, and Centre National de \\ la Recherche Scientifique, Unité Mixte de Recherche 7178, \\ 67087 Strasbourg, France; ${ }^{3}$ Laboratoire Ressources \\ Halieutiques de Sète, Institut Français de Recherche pour \\ l'Exploitation de la MER-Station de Sète, Avenue Jean \\ Monnet, BP 171, 34203 Sète Cedex, France
}

Accepted 6/25/2012; Electronically Published 8/7/2012

\begin{abstract}
Body mass and body condition are often tightly linked to animal health and fitness in the wild and thus are key measures for ecophysiologists and behavioral ecologists. In some animals, such as large seabird species, obtaining indexes of structural size is relatively easy, whereas measuring body mass under specific field circumstances may be more of a challenge. Here, we suggest an alternative, easily measurable, and reliable surrogate of body mass in field studies, that is, body girth. Using 234 free-living king penguins (Aptenodytes patagonicus) at various stages of molt and breeding, we measured body girth under
\end{abstract}

\footnotetext{
*Corresponding author; e-mail: vincent.viblanc@unil.ch.
}

Physiological and Biochemical Zoology 85(5):533-542. 2012. (C) 2012 by The University of Chicago. All rights reserved. 1522-2152/2012/8505-2047\$15.00. DOI: $10.1086 / 667540$ the flippers, body mass, and bill and flipper length. We found that body girth was strongly and positively related to body mass in both molting $\left(R^{2}=0.91\right)$ and breeding $\left(R^{2}=0.73\right)$ birds, with the mean error around our predictions being $6.4 \%$. Body girth appeared to be a reliable proxy measure of body mass because the relationship did not vary according to year and experimenter, bird sex, or stage within breeding groups. Body girth was, however, a weak proxy of body mass in birds at the end of molt, probably because most of those birds had reached a critical depletion of energy stores. Body condition indexes established from ordinary least squares regressions of either body girth or body mass on structural size were highly correlated $\left(r_{\mathrm{s}}=0.91\right)$, suggesting that body girth was as good as body mass in establishing body condition indexes in king penguins. Body girth may prove a useful proxy to body mass for estimating body condition in field investigations and could likely provide similar information in other penguins and large animals that may be complicated to weigh in the wild.

\section{Introduction}

Because body condition is often related to individual health and fitness in wild animals (Potti 1993; Atkinson and Ramsay 1995; Chastel et al. 1995; Dobson and Michener 1995; Merila and Wiggins 1995; Christe et al. 1998; Dobson et al. 1999; Madsen and Shine 1999; Saraux et al. 2011; Balbontín et al. 2012), measuring individual condition is of central interest for physiologists and ecologists (Schulte-Hostedde et al. 2005). Body condition reflects an animal's energy reserves, and information on body reserves can yield important insights on foraging behavior (Kato et al. 2008) and on the quantity of resources extracted from the environment (i.e., energy income), as well as on resource allocation to various functions (Boggs 1992; i.e., energy outcome).

In animals, body condition is classically determined by regressing body mass $\left(M_{\mathrm{b}}\right)$ on some index of structural size using ordinary least squares (OLS) regression (Piersma 1984; see reviews in Brown 1996; Green 2001; Schulte-Hostedde et al. 2005). A high residual $M_{\mathrm{b}}$ implies that the individual is in good condition or has large body reserves because it is heavy relative to its size (Jakob et al. 1996; Schulte-Hostedde et al. 2001).

While noninvasive, this method requires researchers to ob- 
tain both the animal's $M_{\mathrm{b}}$ and an index of structural size. However, in some species, $M_{\mathrm{b}}$ may not always be easy to measure during specific life-history stages and/or under specific field conditions. This is notably the case for large colonial seabirds, particularly heavy species that often incubate their eggs and brood their chicks in windy and rainy locations among numerous and aggressive conspecifics (e.g., Williams 1995; Côté 2000; Kokko et al. 2004). In these colonial species, local conditions may render in situ measurements of $M_{\mathrm{b}}$ (i.e., within the colony) complicated, and displacing individuals from their reproductive site for weighing may result in breeding failure. Researchers would thus benefit from a simple and rapid method for assessing body condition without the need of $M_{\mathrm{b}}$ measurements.

The aim of our study was therefore to determine a reliable general surrogate measure of $M_{\mathrm{b}}$, simple to perform in the field and accurate enough to be substituted for $M_{\mathrm{b}}$ when establishing body condition indexes from OLS regressions with a structural size index. For this purpose, we established a general proxy for body mass using king penguins (Aptenodytes patagonicus) as our model species. The king penguin's annual cycle is made up of periods spent fasting for weeks on land (essentially for molting or breeding) and periods spent foraging at sea to replenish the lost body reserves (Stonehouse 1960; Weimerskirch et al. 1992). Thus, the king penguin presents a particularly relevant model to establish body condition indexes based on structural size and on a dynamic proxy for $M_{\mathrm{b}}$ because large changes in $M_{\mathrm{b}}$ occur in this species as part of its natural life history (Groscolas 1990; Cherel et al. 1994a, 1994b; Groscolas and Robin 2001). In a previous study, Halsey et al. (2008) used structural size indexes (beak, flipper, and tarsus length) to estimate $M_{\mathrm{b}}$ of breeding fasting king penguins but only at the point of critical energy store depletion, that is, critical $M_{\mathrm{b}}$. Here, we focused on estimates of $M_{\mathrm{b}}$ and body condition above critical $M_{\mathrm{b}}$ for breeding as well as molting penguins. Our proxy to $M_{\mathrm{b}}$ was based on a measure of bird corpulence, that is, body girth $\left(G_{\mathrm{b}}\right)$, measured under the flippers. The rational for choosing $G_{\mathrm{b}}$ as an index of $M_{\mathrm{b}}$ and body condition was based on the fact that changes in $G_{\mathrm{b}}$ in king penguins may reflect changes in both fat and muscle (thus protein) mass. Indeed, in penguins, fat reserves are mostly subcutaneous, being distributed more or less regularly all over the body, including the thoracic region (Groscolas 1990), so that $G_{\mathrm{b}}$ probably varies with the width of fat layer and thus fat mass. On the other hand, body proteins are stored mainly in pectoralis muscles and also in the integument (Cherel et al. 1994b), suggesting that $G_{\mathrm{b}}$ may also be a good indicator of protein stores. Contingent with the idea that estimating body condition requires obtaining both the animal's $M_{\mathrm{b}}$ and an index of structural size, our aim was to investigate the relationship between $M_{\mathrm{b}}$ and $G_{\mathrm{b}}$ at different stages of the annual cycle and in both sexes and to test whether $G_{\mathrm{b}}$ could be used as a surrogate measure for $M_{\mathrm{b}}$ for establishing body condition indexes. We first investigated the relationship between $M_{\mathrm{b}}$ and $G_{\mathrm{b}}$ for penguins at different stages of their yearly cycle and made use of the natural changes occurring in $M_{\mathrm{b}}$ and $G_{\mathrm{b}}$ to test whether our predictions showed intraindividual con- sistency, that is, whether changes in $M_{\mathrm{b}}$ were related to changes in $G_{\mathrm{b}}$. We then tested for potential sex effects and investigated whether $G_{\mathrm{b}}$ yielded similar information to $M_{\mathrm{b}}$ when establishing condition indexes in king penguins. We further validated our equations by testing whether we could confidently predict $M_{\mathrm{b}}$ from $G_{\mathrm{b}}$ by (1) using a jackknife approach as previously described by Halsey et al. (2008) and (2) using a test group, that is, individual birds that were different from those used in the calibration process. Working on those two different data sets thus allowed greater confidence in our prediction equations.

\section{Methods}

\section{Data Collection and Data Sets}

Data were collected in the Baie du Marin colony (Possession Island, Crozet Archipelago, $46^{\circ} 25^{\prime} \mathrm{S}, 51^{\circ} 45^{\prime} \mathrm{E}$ ), which is host to ca. 24,000 breeding pairs. Morphometric measurements $\left(M_{\mathrm{b}}\right.$, $G_{\mathrm{b}}$, and bill and flipper length) were obtained from a total of 234 free-living king penguins during three different field seasons in 2000-2001 (year 1; $N=123$ birds), 2009-2010 (year $2 ; N=51$ ), and 2011-2012 (year 3; $N=60$ ). In addition, in 2011-2012, we also obtained repeated morphometric measurements on 10 fasting males that were captured at the onset of breeding and kept captive as part of another study; we used these measurements to validate our equations predicting $M_{\mathrm{b}}$ from $G_{\mathrm{b}}$ (see below).

\section{Morphometric Measurements}

On capture, penguins were transported to a nearby dry shelter (within $10 \mathrm{~m}$ of the colony), and $M_{\mathrm{b}}$ was measured to the nearest $\pm 2 \mathrm{~g}$; $G_{\mathrm{b}}$ was obtained by measuring the circumference of the body to the nearest $1 \mathrm{~mm}$ just beneath the flippers, surrounding the bird with a flexible tape measure around the pectoralis. All $G_{\mathrm{b}}$ measurements were standardized, performed with the animal in an upright position, and measures were taken when pectoralis circumference was at its maximum (i.e., stretched out during inspiration); $G_{\mathrm{b}}$ was also initially measured at the abdomen $\left(G_{\text {babd }}\right)$, but the relationship between $G_{\text {babd }}$ and $M_{\mathrm{b}}$ proved variable between years and experimenters, and thus we dropped $G_{\text {babd }}$ from further analyses. Classic measurements of bill length (using dial caliper from bill tip to the point of the jaw) and flipper length (using a solid metal ruler, flipper fully extended, from the sternum to its tip) were also obtained to the nearest $1 \mathrm{~mm}$ (see Fahlman et al. 2006 for details on those measurements).

\section{Relating Body Mass to Body Girth}

To investigate whether $G_{\mathrm{b}}$ was related to $M_{\mathrm{b}}$ in the king penguin, we used data acquired from the 234 free-living birds. Overall, in these birds, $M_{\mathrm{b}}$ values ranged from 7 to $19 \mathrm{~kg}$, and $G_{\mathrm{b}}$ values ranged from 52 to $78 \mathrm{~cm}$ (see table 1). In year $1, M_{\mathrm{b}}, G_{\mathrm{b}}$, and bill and flipper length were measured in a total of 46 molting and 77 breeding birds. In king penguins, the yearly and massive prebreeding molt lasts around $4 \mathrm{wk}$ and is associated with 
Table 1: Summary data of morphometric measurements performed on 234 adult king penguins (Aptenodytes patagonicus) sampled on Possession Island in the Crozet Archipelago

\begin{tabular}{|c|c|c|c|c|c|}
\hline Bird status & $N$ & $\begin{array}{c}\text { Body mass } \\
M_{\mathrm{b}}(\mathrm{g} ; \text { range })\end{array}$ & $\begin{array}{c}\text { Body girth } \\
G_{\mathrm{b}}(\mathrm{cm} ; \text { range })\end{array}$ & $\begin{array}{l}\text { Bill length } \\
(\mathrm{cm} ; \text { range })\end{array}$ & $\begin{array}{l}\text { Flipper length } \\
(\mathrm{cm} \text {; range })\end{array}$ \\
\hline Premolt & 10 & $\begin{array}{c}17,186 \pm 368 \\
(14,974-18,596)\end{array}$ & $\begin{array}{c}72.7 \pm .9 \\
(69.0-77.5)\end{array}$ & $\begin{array}{c}128.9 \pm 1.9 \\
(119.0-137.0)\end{array}$ & $\begin{array}{c}322.3 \pm 2.2 \\
(311.0-330.0)\end{array}$ \\
\hline Molt onset & 8 & $\begin{array}{c}13,952 \pm 407 \\
(11,994-15,244)\end{array}$ & $\begin{array}{l}66.8 \pm 1.1 \\
(62.5-70.2)\end{array}$ & $\begin{array}{c}127.9 \pm 2.5 \\
(115.0-139.0)\end{array}$ & $\begin{array}{c}312.6 \pm 3.6 \\
(300.0-324.0)\end{array}$ \\
\hline Midmolt & 12 & $\begin{array}{c}13,479 \pm 431 \\
(11,032-15,560)\end{array}$ & $\begin{array}{c}64.2 \pm .7 \\
(58.8-68.0)\end{array}$ & $\begin{array}{c}127.6 \pm 1.2 \\
(122.0-134.0)\end{array}$ & $\begin{array}{c}317.3 \pm 3.3 \\
(295.0-334.0)\end{array}$ \\
\hline Molt end & 76 & $\begin{array}{c}9,227 \pm 132 \\
(7,148-14,068)\end{array}$ & $\begin{array}{c}56.8 \pm .3 \\
(52.0-67.0)\end{array}$ & $\begin{array}{c}129.2 \pm .8 \\
(115.0-147.0)\end{array}$ & $\begin{array}{c}324.2 \pm 1.2 \\
(300.0-355.0)\end{array}$ \\
\hline Prebreeding & 14 & $\begin{array}{c}11,708 \pm 311 \\
(10,042-13,904)\end{array}$ & $\begin{array}{c}61.5 \pm .5 \\
(59.0-64.0)\end{array}$ & $\begin{array}{c}128.5 \pm 2.0 \\
(112.0-139.0)\end{array}$ & $\begin{array}{c}320.4 \pm 2.7 \\
(332.0-339.0)\end{array}$ \\
\hline Courting & 55 & $\begin{array}{l}12,063 \pm 205 \\
(8,096-15,142)\end{array}$ & $\begin{array}{c}62.9 \pm .4 \\
(54.5-68.5)]\end{array}$ & $\begin{array}{c}126.2 \pm .8 \\
(111.0-136.0)\end{array}$ & $\begin{array}{c}322.1 \pm 1.6 \\
(290.0-343.0)\end{array}$ \\
\hline Incubating & 26 & $\begin{array}{l}10,174 \pm 238 \\
(8,426-12,832)\end{array}$ & $\begin{array}{c}59.3 \pm .4 \\
(55.0-65.0)\end{array}$ & $\begin{array}{c}129.3 \pm 1.0 \\
(110.0-138.0)\end{array}$ & $\begin{array}{c}322.4 \pm 1.6 \\
(306.0-339.0)\end{array}$ \\
\hline Brooding & 63 & $\begin{array}{l}12,095 \pm 283 \\
(8,796-18,936)\end{array}$ & $\begin{array}{c}62.5 \pm .4 \\
(57.0-70.6)\end{array}$ & $\begin{array}{c}126.1 \pm .8 \\
(117.0-142.0)\end{array}$ & $\begin{array}{c}321.3 \pm 1.4 \\
(287.0-346.0)\end{array}$ \\
\hline
\end{tabular}

Note. The 30 birds that were measured at molt end were caught and remeasured either as prebreeders or as courting birds, which explains the larger sample size if all $N$ are summed. Data are given as means \pm SE.

prolonged onshore fasting, during which birds lose about $40 \%$ of their body mass (Cherel et al. 1994a). From their plumage aspect, molting birds (unknown sex) were categorized as individuals in premolt (i.e., new feathers growing beneath the skin but no old feathers shed; $N=10$ ), at molt onset (i.e., ruffled plumage, a few breast feathers lost; $N=8$ ), midmolt (i.e., breast, back, and hip feathers lost; $N=12$ ), or molt end before departure to sea to refeed (i.e., new plumage, a few remnants of old plumage on the head, new tail not completely grown; $N=16$ ). Breeding birds were measured as courting birds, that is, after having been fasting ashore for a few days at the onset of breeding ( 22 males and 17 females, which were sexed according to breeding phenology; Stonehouse 1960), incubating birds $(N=17$, unknown sex), or chick-brooding birds $(N=21$, unknown sex). Incubating birds were measured at partner relief, when leaving the colony after an incubation shift of approximately $15 \mathrm{~d}$. Brooding birds were measured when arriving ashore to resume their parental shift on the chick, after having foraged at sea for 8-15 d. In year 2, the same measurements were obtained on 51 breeding birds (9 incubating and 42 chick-brooding birds). Those birds were sexed from breeding phenology ( 28 males and 23 females) and DNA analysis (Griffiths et al. 1998) and measured when leaving the colony at the end of a breeding shift (at partner relief). In addition, 40 of the 51 birds were recaptured and measured when returning to the colony to start their subsequent breeding shift, after foraging at sea for $14.5 \pm 0.7 \mathrm{~d}$ (mean \pm SE). Finally, during year 3, we captured and measured a total of 60 unsexed birds at the end of the molt process. Of those, 30 were remeasured $24.1 \pm 0.6 \mathrm{~d}$ later as they returned to the colony to breed (i.e., 14 prebreeding birds that had not yet started courting and 16 birds actively engaged in courtship).

Pooling all data, we used a linear mixed model (LMM) analysis to determine whether $G_{\mathrm{b}}$ accurately related to $M_{\mathrm{b}}$ and whether this relationship depended on the molting, reproductive, and nutritional (mainly fasting duration) status of the animals. We thus specified $M_{\mathrm{b}}$ as the dependent variable and $G_{\mathrm{b}}$ and status as the independent variables and considered the statistical interaction between $G_{\mathrm{b}}$ and status. Because birds were sampled by different experimenters in different years, year was added as a cofactor in the model to test whether predictions of $M_{\mathrm{b}}$ from $G_{\mathrm{b}}$ were consistent between years (and thus experimenters). Bird identity was added as a random factor in order to control for repeated measurements on the 70 birds that had been sampled twice in years 2 and 3 . Whenever interactions were significant, we used separate linear regression models (LMs) to analyze how changes in molting or breeding status might affect $M_{\mathrm{b}}$ predictions from $G_{\mathrm{b}}$. Estimated slopes were then calculated and compared using 95\% confidence intervals $\left(\mathrm{CI}_{95}\right)$.

\section{Sex Effects}

We used the 90 free-living birds for which sex was determined in years 1 and 2 to investigate whether sex affected the predictions of $M_{\mathrm{b}}$ from $G_{\mathrm{b}}$. The relationship between $M_{\mathrm{b}}$ and $G_{\mathrm{b}}$ was tested separately in males and females using linear regressions, and the slopes of both regressions were then compared using $\mathrm{CI}_{95}$. 


\section{Estimating Changes in Body Mass from Changes in Body Girth}

We further investigated whether changes in $G_{\mathrm{b}}$ reliably reflected changes in $M_{\mathrm{b}}$ (i.e., whether $G_{\mathrm{b}}$ variation could be used consistently as a predictor of $M_{\mathrm{b}}$ variation within individuals), using the free-living individuals that were captured twice in year 2 $(N=40$, measured after a breeding shift and then at return to the colony for the next breeding shift) and year $3(N=$ 30 , measured at molt end and then at return to the colony for breeding). We calculated the change in $M_{\mathrm{b}}$ and $G_{\mathrm{b}}$ that occurred during a foraging sojourn at sea and regressed changes in $M_{\mathrm{b}}$ on changes in $G_{\mathrm{b}}$.

\section{Using Body Girth to Establish Condition Indexes}

To test whether $G_{\mathrm{b}}$ could be used as a reliable surrogate measure for $M_{\mathrm{b}}$ when establishing condition indexes along with measures of structural size in penguins, we separately regressed $M_{\mathrm{b}}$ and $G_{\mathrm{b}}$ on structural size using all data obtained on free-living birds. The residuals obtained from both regressions gave us a measure of $M_{\mathrm{b}}$ or $G_{\mathrm{b}}$ controlled for structural size, that is, a classical body condition index (Schulte-Hostedde et al. 2005). The residuals obtained from both regressions were then correlated to see whether they yielded the same information. Because our measures of structural size (bill and flipper length) were strongly correlated (Pearson's $r=0.56 ; t=11.6, \mathrm{df}=$ $303, P<0.001)$, we used the first component of a principal component analysis between bill and flipper length as our structural size index (SSI; Saraux et al. 2011). This component explained $85 \%$ of the variation, and factor loading was as follows: SSI $=$ PC1 $=0.93 \times$ flipper $+0.38 \times$ beak.

\section{Study Validation}

We assessed the error associated with our predictions of $M_{\mathrm{b}}$ from $G_{\mathrm{b}}$ using two different methods. First, on free-living birds, we used a jackknife approach as presented by Halsey et al. (2008). In this approach, we used the same birds for which the predictive equation was established in order to validate it (see Halsey et al. 2008 for details). Briefly, all data were pooled, and we regressed $M_{\mathrm{b}}$ on $G_{\mathrm{b}}$ a total of 305 times (i.e., once per case for which we had both $M_{\mathrm{b}}$ and $G_{\mathrm{b}}$ ), each time removing a different data point from the analysis. The predicting equation was then used to predict $M_{\mathrm{b}}$ from $G_{\mathrm{b}}$ for the data point that had been removed. We then tested how well observed and predicted $M_{\mathrm{b}}$ were correlated, and the absolute percentage error of our estimates was calculated as [ $\left(\right.$ observed $M_{\mathrm{b}}$ - predicted $\left.M_{\mathrm{b}}\right) /$ observed $M_{\mathrm{b}}$ ] $\times 100$.

Second, we tested whether our equations yielded reasonable estimates of $M_{\mathrm{b}}$ when used in a test group, that is, in birds different from those used for the calibration. For this, we used the data obtained from the 10 males that had been caught at the onset of breeding in year 3 and kept fasting in a pen for

Table 2: Estimates of linear mixed model specifying king penguin body mass $\left(M_{\mathrm{b}}\right)$ as dependent variable; body girth $\left(G_{\mathrm{b}}\right)$, bird status (i.e., breeding or molting stages), and interaction between $G_{\mathrm{b}}$ and bird status as independent variables; year as cofactor; and individual identity as random factor

\begin{tabular}{lrrrc}
\hline & Estimate $\pm \mathrm{SE}$ & $\mathrm{df}$ & \multicolumn{1}{c}{$t$} & $P$ \\
\hline Intercept & $-13,613.8 \pm 1,882.5$ & 224 & -7.23 & $<.001$ \\
Year $_{2010-2011}$ & $-424.3 \pm 304.0$ & 224 & -1.40 & .16 \\
Year $_{2011-2012}$ & $-224.9 \pm 164.5$ & 224 & -1.37 & .17 \\
$G_{\mathrm{b}}$ & $\mathbf{4 1 1 . 8} \pm \mathbf{2 9 . 5}$ & $\mathbf{6 3}$ & $\mathbf{1 3 . 9 7}$ & $<. \mathbf{0 0 1}$ \\
Premolt & $4,575.1 \pm 7,537.8$ & 224 & .61 & .54 \\
Molt onset & $\mathbf{1 4 , 5 4 8 . 0} \pm \mathbf{6 , 8 4 8 . 1}$ & $\mathbf{2 2 4}$ & $\mathbf{2 . 1 2}$ & $\mathbf{. 0 3}$ \\
Midmolt & $741.7 \pm 6,991.6$ & 224 & .11 & .91 \\
Molt end & $4,895.5 \pm 2,855.5$ & 63 & 1.71 & .09 \\
Prebreeding & $-\mathbf{1 1 , 0 5 7 . 3} \pm \mathbf{3 , 8 1 1 . 7}$ & $\mathbf{6 3}$ & $-\mathbf{2 . 9 0}$ & $\mathbf{. 0 0 5}$ \\
Courtship & $-2,542.1 \pm 2,935.9$ & 63 & -.87 & .39 \\
Incubation & $-4,519.7 \pm 3,192.4$ & 224 & -1.42 & .16 \\
$G_{\mathrm{b}} \times$ old plumage & $-50.9 \pm 104.6$ & 224 & -.49 & .63 \\
$G_{\mathrm{b}} \times$ molt onset & $-\mathbf{2 1 6 . 9} \pm \mathbf{1 0 2 . 8}$ & $\mathbf{2 2 4}$ & $-\mathbf{2 . 1 1}$ & $\mathbf{. 0 4}$ \\
$G_{\mathrm{b}} \times$ midmolt & $-1.5 \pm 108.8$ & 224 & -.01 & .99 \\
$G_{\mathrm{b}} \times$ molt end & $-92.6 \pm 47.2$ & 63 & -1.96 & .054 \\
$G_{\mathrm{b}} \times$ prebreeding & $\mathbf{1 8 9 . 1} \pm \mathbf{5 9 . 4}$ & $\mathbf{6 3}$ & $\mathbf{3 . 1 8}$ & $\mathbf{. 0 0 2}$ \\
$G_{\mathrm{b}} \times$ courtship & $37.6 \pm 46.4$ & 63 & .81 & .42 \\
$G_{\mathrm{b}} \times$ incubation & $69.0 \pm 51.1$ & 63 & 1.35 & .18 \\
\hline
\end{tabular}

Note. The $R^{2}$ of the model, calculated as the squared correlation between the fitted and observed values, was 0.89 . Number of observations, $n=305$; number of birds, $N=234$. Significant values are given in bold. 
up to $37 \mathrm{~d}$ (mean $=26.7$, range $=16-37 \mathrm{~d})$. A total of 79 measures of $M_{\mathrm{b}}$ and $G_{\mathrm{b}}$ (six to nine measures per bird) was performed. Using the measured $G_{b}$, we predicted a total of 79 $M_{\mathrm{b}}$ 's and investigated how those predicted values related to measured values of $M_{\mathrm{b}}$ using an LMM with bird identity set as a random factor. The percentage error of our prediction was calculated as above.

\section{Statistics}

All analyses were performed in R (ver. 2.14.0; R Development Core Team 2011). When data were pooled, analysis was performed with LMMs using the "nlme" package in R (Pinheiro et al. 2011). For LMMs, $R^{2}$ values were estimated by looking at the squared correlation between the fitted and observed values. Principal component analysis was performed using the "stats" package in R. Whenever appropriate, break points in the data were identified using the "segmented" package in $\mathrm{R}$ (Muggeo 2003, 2008). Normality of residuals was asserted using the Shapiro-Wilk test for normality. Results are reported as means \pm SE. Significant results are for $P<0.05$. Number of observations $(n)$ and number of birds $(N)$ are reported whenever appropriate.

\section{Ethical Note}

Upon capture, the bird's head was immediately covered with a hood to keep it calm throughout handling. After weighing and measurements were done, we quickly returned the bird to the colony. Manipulations lasted between 5 and $10 \mathrm{~min}$, and care was taken not to disturb incubating birds. All procedures were approved by the Ethical Committee of the Institut Polaire Français, Paul-Emile Victor. Authorization to enter the colony and to manipulate birds was obtained from Terres Australes et Antarctiques Françaises. The experiments comply with the current laws of France.

\section{Results}

\section{Relating Body Mass to Body Girth}

When pooling all data and controlling for repeated measures in our model, we found a strong and positive relationship between $G_{\mathrm{b}}$ and $M_{\mathrm{b}}$ in king penguins (LMMs; $R^{2}=0.89$; table 2; fig. 1). The influence of year was not significant in our model, suggesting that $G_{\mathrm{b}}$ was a robust predictor of $M_{\mathrm{b}}$, regardless of who performed the measurements (i.e., different experimenters in each year) and/or direct year effects. Importantly, both bird status and the statistical interaction between $G_{\mathrm{b}}$ and bird status were significant (table 2), suggesting that the relationship between $G_{\mathrm{b}}$ and $M_{\mathrm{b}}$ differed significantly depending on the birds' status. Thus, pooling years, we investigated differences for birds measured at different molting or breeding stages using linear regressions. Overall, slopes of regression appeared to be lower for molting than breeding birds, the difference being especially marked when comparing birds at the end of molt to birds at the prebreeding to brooding stages (shown by the lack of substantial overlap in $\mathrm{CI}_{95}$; table 3 ). This indicates that individuals with increasing girth were disproportionately heavier when breeding than when molting. To account for substantial dif-

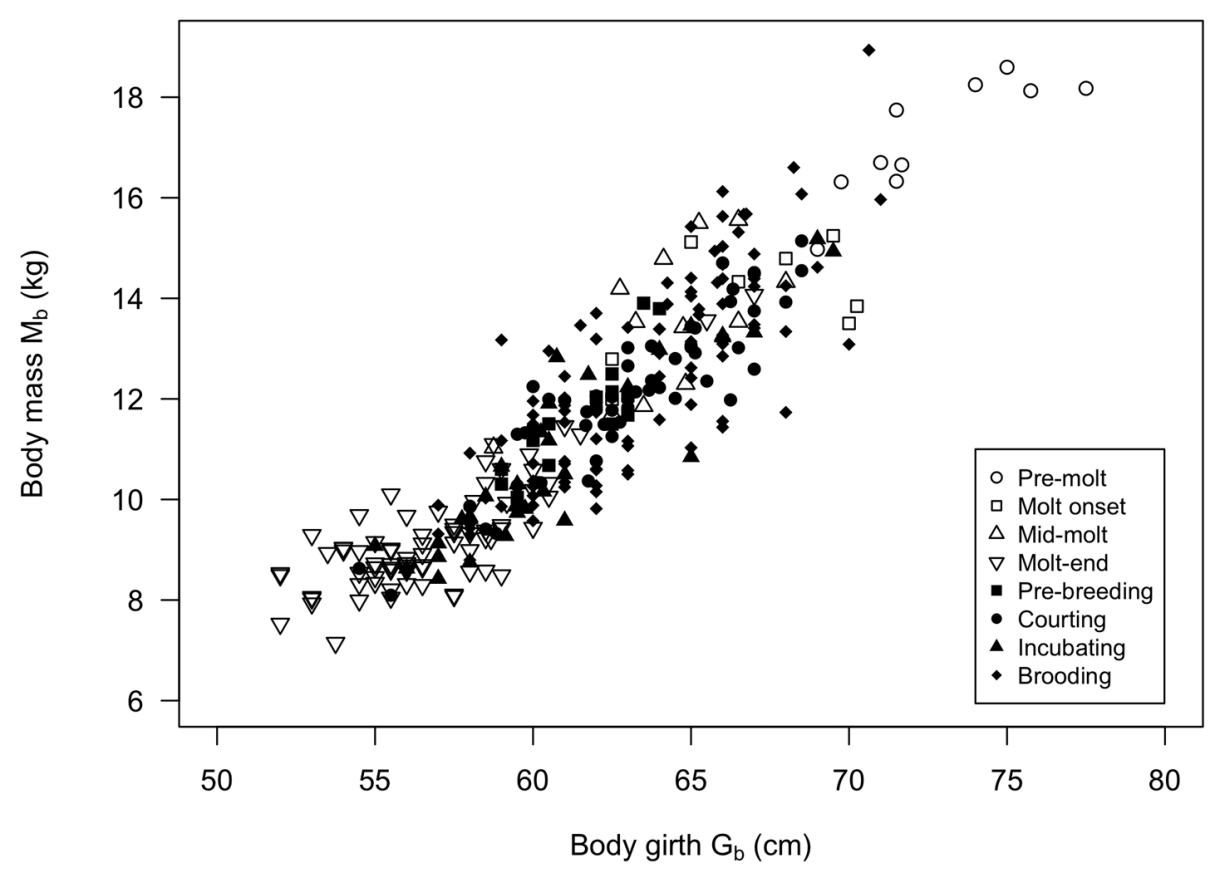

Figure 1. Relationship between body mass $\left(M_{\mathrm{b}}\right)$ and body girth $\left(G_{\mathrm{b}}\right)$ in king penguins. Data are for birds measured at various stages of molt (premolt, molt onset, midmolt, and molt end) and various stages of reproduction (prebreeding, courting, incubating, and brooding). 
Table 3: Slope estimates and 95\% confidence intervals $\left(\mathrm{CI}_{95}\right)$ for linear regressions of body mass on body girth in king penguins at different stages of molt and breeding (see also fig. 1)

\begin{tabular}{lrrccc}
\hline Stage & Intercept & Slope & Slope $\mathrm{CI}_{95}$ & $P$ & $R^{2}$ \\
\hline Premolt & $-9,038.7$ & 360.9 & $209.4-512.3$ & .002 & .73 \\
Molt onset & 934.2 & 194.9 & $-48.2-438.0$ & .17 & .29 \\
Midmolt & 410.3 & 148.9 & $118.5-702.0$ & .02 & .43 \\
Molt end & 336.6 & 28.6 & $280.5-392.7$ & $<.001$ & .65 \\
Prebreeding & $-24,691.6$ & 591.5 & $408.3-774.8$ & $<.001$ & .77 \\
Courtship & $-15,938.1$ & 444.9 & $390.8-499.1$ & $<.001$ & .83 \\
Incubation & $-17,256.6$ & 463.0 & $389.8-536.3$ & $<.001$ & .83 \\
Brooding & $-18,609.5$ & 490.6 & $414.4-566.8$ & $<.001$ & .64 \\
\hline
\end{tabular}

ferences in slopes (see $\mathrm{CI}_{95}$; table 3 ) between molting or breeding categories, we derived two separate equations predicting $M_{\mathrm{b}}$ (in g) from $G_{\mathrm{b}}$ (in $\mathrm{cm}$ ): one for molting birds $\left(\mathrm{eq}_{\mathrm{molt}}\right.$ ): $M_{\mathrm{b}}=-17,256 \pm 875+468.9 \pm 14.5 \times G_{\mathrm{b}} \quad\left(\mathrm{LM} ; R^{2}=0.91 ;\right.$ $\left.F_{1,104}=1,039, P<0.001\right)$ and one for breeding birds $\left(\mathrm{eq}_{\mathrm{breed}}\right)$ : $M_{\mathrm{b}}=-18,226 \pm 1,329+482.9 \pm 21.1 \times G_{\mathrm{b}}\left(\mathrm{LM} ; R^{2}=0.73\right.$; $\left.F_{1,197}=521.1, P<0.001\right)$.

In addition, and due mostly to birds at the end of molt, an apparent break point in the data could be seen around a $G_{b}$ of approximately $60 \mathrm{~cm}$ (fig. 1). For molting birds, break point analysis revealed a change in slope when $G_{\mathrm{b}}$ was $56.8 \pm 0.7 \mathrm{~cm}$ (fig. 2), corresponding to the average $G_{b}$ of birds at the end of molt (see table 1). The pre-break point regression equation (corresponding to birds with a $G_{\mathrm{b}}$ lower than $57 \mathrm{~cm}$ ) was $\mathrm{eq}_{\mathrm{molt1}}$ : $M_{\mathrm{b}}=1,031.0 \pm 3,387.1+139.1 \pm 61.7 \times G_{\mathrm{b}}$, whereas the post-break point regression equation (corresponding to birds with a $G_{\mathrm{b}}$ higher than $57 \mathrm{~cm}$ ) was $\mathrm{eq}_{\text {molt2 }}: M_{\mathrm{b}}=-20,531.3 \pm$ $1,405.0+518.6 \pm 22.1 \times G_{\mathrm{b}}$ (see fig. 2). Whereas $G_{\mathrm{b}}$ and $M_{\mathrm{b}}$ were strongly associated above the $57-\mathrm{cm}$ break point (LM; $\left.R^{2}=0.90 ; F_{1,61}=549.6, P<0.001\right)$, the relationship was weak below this point $\left(\mathrm{LM} ; R^{2}=0.11 ; F_{1,41}=5.08, P=0.03\right)$, suggesting that $G_{\mathrm{b}}$ was not a good predictor of $M_{\mathrm{b}}$ for values below $57 \mathrm{~cm}$, that is, for $M_{\mathrm{b}}<9.3 \mathrm{~kg}$ (calculated from $\mathrm{eq}_{\text {molt2 }}$ ). No clear break point was observed for breeding birds (see fig. 2).

\section{Sex Effect}

From the 90 birds that were sexed in years 1 and 2, we found no significant differences for the relationship between $M_{\mathrm{b}}$ and $G_{\mathrm{b}}$ according to sex; $G_{\mathrm{b}}$ strongly predicted $M_{\mathrm{b}}$ in males (LM; $\left.R^{2}=0.71 ; F_{1,48}=116.9, P<0.001\right)$ and females (LM; $R^{2}=$ $\left.0.70 ; F_{1,38}=88.6, P<0.001\right)$, and the slopes of the relationships were not significantly different. Indeed, $\mathrm{CI}_{95}$ overlapped substantially, that is, $431.3 \pm 39.9, \mathrm{CI}_{95}=353.2-509.7$, for males and $378.6 \pm 40.2, \mathrm{CI}_{95}=299.8-475.5$, for females.

\section{Predicting Changes in Body Mass from Changes in Body Girth}

In the 70 birds that were measured twice in years 2 and 3, that is, before leaving for foraging at sea and at their subsequent return to the colony some $2-3$ wk later, we found that changes in $M_{\mathrm{b}}$ could be predicted by changes in $G_{\mathrm{b}}$ (LMs; $R^{2}=0.32$; $F_{1,68}=31.8, P<0.001$; fig. 3 ), suggesting that the estimation of $M_{\mathrm{b}}$ from $G_{\mathrm{b}}$ was consistent within individuals. The associated equation was $\delta M_{\mathrm{b}}(\mathrm{g})=-1,923 \pm 236+206.7 \pm 36.7 \times$ $\delta G_{\mathrm{b}}(\mathrm{cm})$. Thus, a change in $G_{\mathrm{b}}$ of $1 \mathrm{~cm}$ was associated with a change in $M_{\mathrm{b}}$ of approximately $207 \mathrm{~g}$.

\section{Using Body Girth to Estimate Body Condition in King Penguins}

Regressions of $M_{\mathrm{b}}$ or $G_{\mathrm{b}}$ on the SSI were both significant (LMs; $F_{1,303}=12.2$ and 5.7, $P<0.001$ and 0.01 , for regressions with $M_{\mathrm{b}}$ or $G_{\mathrm{b}}$, respectively). The residuals of both regressions were highly correlated (Spearman's rank correlation, $r=0.92 ; P<$ 0.001 ; fig. 4), suggesting that $M_{\mathrm{b}}$ and $G_{\mathrm{b}}$ could be used interchangeably to establish body condition indexes in concert with structural size measures in king penguins. Removing birds at the end of molt (birds below the $57-\mathrm{cm}$ break point in $G_{\mathrm{b}}$ ) from the analyses did not substantially change the results $(r=0.85 ; P<0.001)$.

\section{Testing Our Predictions}

Using a jackknife approach (Halsey et al. 2008) on the 305 cases for which we had both $M_{\mathrm{b}}$ and $G_{\mathrm{b}}$ and using $\mathrm{eq}_{\mathrm{molt}}$ and eq $\mathrm{breed}_{\text {to }}$ to predict the body mass of molting and breeding birds, respectively, we found that predicted $M_{\mathrm{b}}$ was highly correlated with observed $M_{\mathrm{b}}$ (Spearman's rank correlation, $r=0.92$; $P<0.001$; fig. 5A). The mean absolute percentage error of our predictions was $6.4 \% \pm 0.3 \%$ (range: $0.04 \%-24.5 \%$ ), and the percentage error distribution for our estimates was normal ( $P=0.27$ ), suggesting that our predicted $M_{\mathrm{b}}$ did not systematically under- or overestimate measured $M_{\mathrm{b}}$. Again, removing birds at the end of molt from the analysis did not substantially change the results $(r=0.87$; mean absolute percentage error $=6.3 \% \pm 0.3 \%)$.

In the 10 captive males caught at the onset of reproduction, we found a strong relationship between measured $M_{\mathrm{b}}$ and $M_{\mathrm{b}}$ as estimated from $G_{\mathrm{b}}$ using the $\mathrm{eq}_{\text {breed }}$ equation (LMM; $R^{2}=$ $0.71 ; t=12.50, P<0.001$; fig. $5 B)$. The mean absolute percentage error was remarkably close to that reported using the jackknife approach, that is, $6.3 \% \pm 0.5 \%$ (range: $0.1 \%-22.0 \%$ ), and the percentage error for our estimates was normally distributed as well $(P=0.41)$.

\section{Discussion}

Our study aimed at validating the use of a surrogate measure for body mass when estimating body condition in species for which an accurate measure of $M_{\mathrm{b}}$ may be difficult to obtain under field conditions. Our results suggest that the simple measure of $G_{\mathrm{b}}$ may provide an accurate and reliable candidate. In king penguins, $G_{\mathrm{b}}$ can be measured without having to move the animal from its breeding territory and with minimal disturbance, provided care is taken to measure the animal in a 

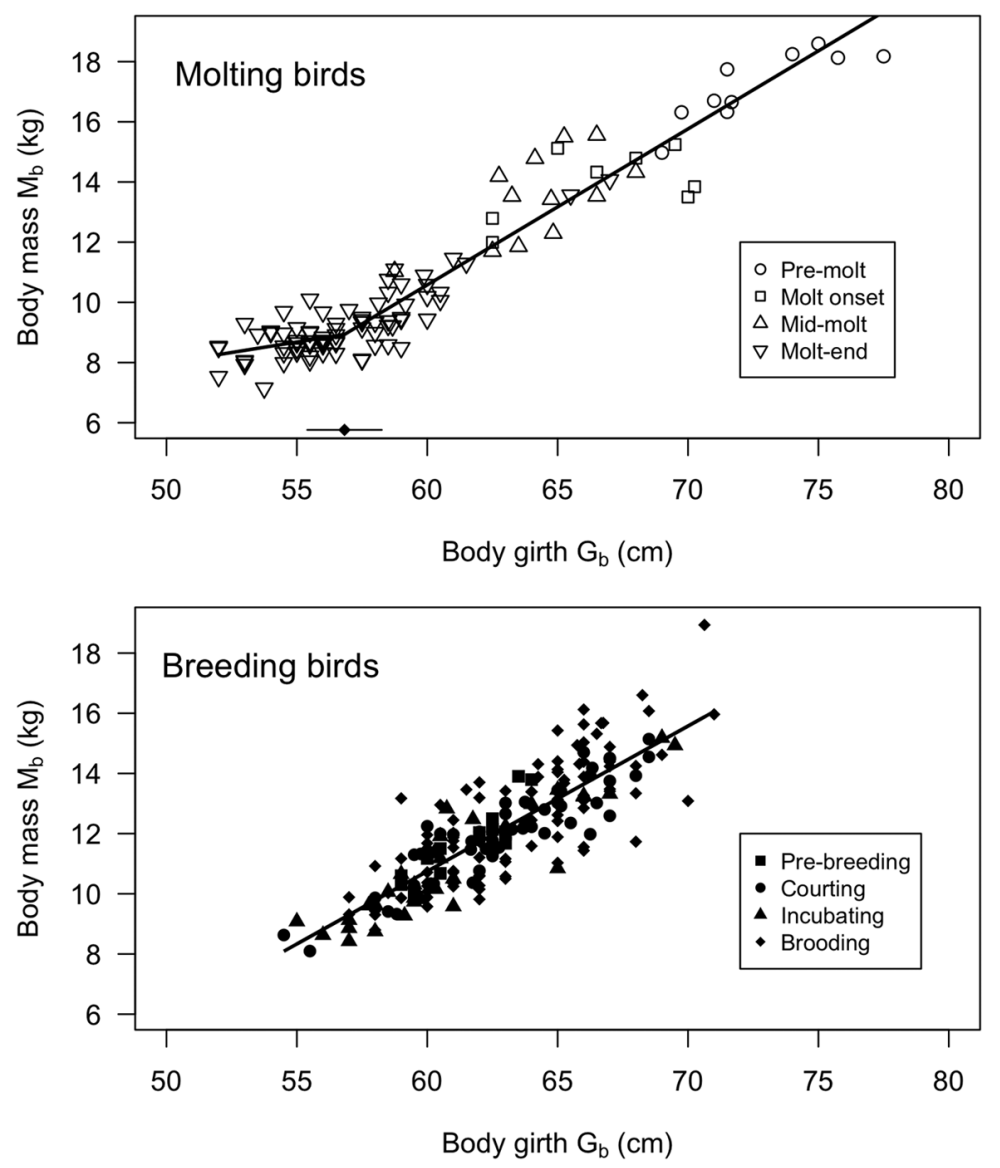

Figure 2. Segmented regression analyses between body mass $\left(M_{\mathrm{b}}\right)$ and body girth $\left(G_{\mathrm{b}}\right)$ for molting and breeding king penguins. The top panel shows a two-step (segmented) linear relationship between $M_{\mathrm{b}}$ and $G_{\mathrm{b}}$ for molting birds, with estimated break point ( \pm SE) reported along the $X$-axis. The bottom panel shows a single linear relationship between $M_{\mathrm{b}}$ and $G_{\mathrm{b}}$ for breeding birds. Data are for birds measured at various stages of molt (premolt, molt onset, midmolt, and molt end) and various stages of reproduction (prebreeding, courting, incubating, and brooding).

standardized position (e.g., upright king penguin sitting on its egg). Conversely, this may be one of the drawbacks when measuring $G_{\mathrm{b}}$ in situations where animals are crouched, lying flat on eggs, or highly nervous and agitated. Nonetheless, our results show that $G_{\mathrm{b}}$ strongly predicted $M_{\mathrm{b}}$ in king penguins, regardless of year (i.e., different experimenters and different years), sex, and stage within molting or breeding groups (though the relationship was not as good for birds at the end of molt, as discussed below). These findings suggest that $G_{\mathrm{b}}$ is a relatively robust estimator of $M_{\mathrm{b}}$ in different situations. As stated in the "Introduction," this strong correlation between $M_{\mathrm{b}}$ and $G_{\mathrm{b}}$ is likely due to the fact that $G_{\mathrm{b}}$ changes mostly in relation to the width of the subcutaneous fat layer and also to the mass of the pectoralis muscles and the integument. These two traits are indeed the two major protein stores in king penguins and thereby the two main contributors to the changes in $M_{\mathrm{b}}$ during foraging or fasting (Cherel et al. 1994b). Importantly, we found some significant effects of specific physiological states on the relationship between $G_{\mathrm{b}}$ and $M_{\mathrm{b}}$, with molting and breeding birds appearing to differ slightly. In this context, we derived two different equations for predicting $M_{\mathrm{b}}$ from $G_{\mathrm{b}}$. The slightly lower slope coefficient obtained for molting birds suggests that a similar $G_{\mathrm{b}}$ is associated with slightly lower $M_{\mathrm{b}}$ in molting than in breeding birds. Such a difference might be explained by the fact that changes in $G_{\mathrm{b}}$ in molting birds may be in part a reflection of the molt process, including a more or less ruffled plumage. Indeed, in molting penguins, feather synthesis first occurs under the skin and contributes to increasing the thickness of the skin/subcutaneous fat/feather layer and consequently $G_{\mathrm{b}}$ (Groscolas 1978; Groscolas and Cherel 1991; Cherel et al. 1994a). Thus, before the emergence of the new feathers from under the skin, variations in $G_{\mathrm{b}}$ are likely not only linked to variations in energy reserves but partly linked to the molt process itself. In other words, at the beginning of the molt, $G_{\mathrm{b}}$ likely overestimates $M_{\mathrm{b}}$ and actual energy reserves.

Also in molting birds, we noted a break point in the data set at a $G_{\mathrm{b}}$ of $57 \mathrm{~cm}$, which corresponded to an $M_{\mathrm{b}}$ of approximately $9.3 \mathrm{~kg}$. Below this break point, $G_{\mathrm{b}}$ poorly predicted $M_{\mathrm{b}}$. Interestingly, this $9.3-\mathrm{kg} M_{\mathrm{b}}$ is similar to the critical $M_{\mathrm{b}}$ $\left(\mathrm{c} M_{\mathrm{b}}\right)$ determined in breeding king penguins at a critical energy 


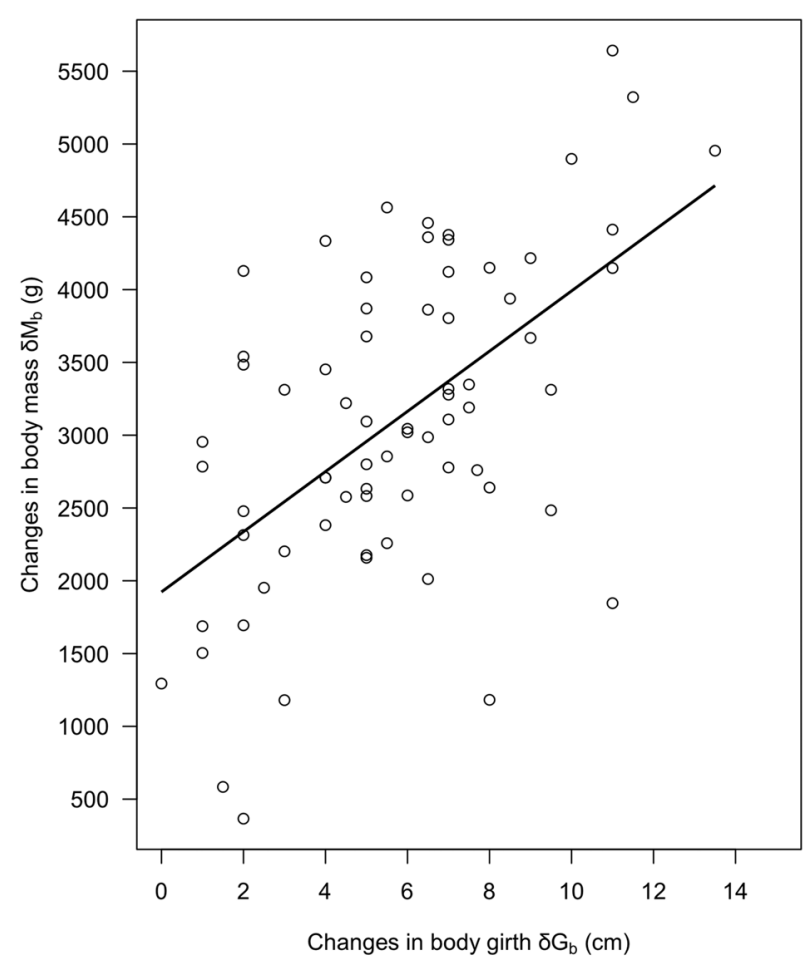

Figure 3. Changes in body mass $\left(\delta M_{\mathrm{b}}\right)$ versus changes in body girth $\left(\delta G_{\mathrm{b}}\right)$ during a foraging sojourn at sea in king penguins. Data were obtained from 70 birds that were first measured when leaving the colony for refeeding at sea (either at the end of molt or at the end of a breeding shift) and then remeasured when subsequently returning ashore. The regression line for predicting $\delta M_{\mathrm{b}}$ from $\delta G_{\mathrm{b}}$ is shown $\left(R^{2}=0.32 ; F_{1,68}=31.8, P<0.001\right)$.

store depletion stage (Cherel et al. 1994b; Gauthier-Clerc et al. 2001; Halsey et al. 2008). Thus, a possible explanation for the poor prediction of $M_{\mathrm{b}}$ from $G_{\mathrm{b}}$ at the end of molt may be that below the $\mathrm{c} M_{\mathrm{b}}$, changes in $G_{\mathrm{b}}$ are no longer (or only slightly) associated with changes in $M_{\mathrm{b}}$ and by extension energy stores, because the animal has virtually depleted its energy stores at that advanced stage of fasting. Below the $c M_{\mathrm{b}}$, an animal's $M_{\mathrm{b}}$ would then essentially reflect the mass of its lean tissues, and variation in $M_{\mathrm{b}}$ would be linked to variations in structural size other than $G_{\mathrm{b}}$ and not to changes in energy reserves and body condition. We did not observe a clear break point in the $M_{\mathrm{b}}$ versus $G_{\mathrm{b}}$ relationship for breeding birds. However, this is probably explained by the small number of breeding birds $(N=$ 10) sampled at an $M_{b}$ below the $c M_{b}$, and the existence of a similar break point is likely. Thus, predicting $M_{\mathrm{b}}$ from $G_{\mathrm{b}}$ should be avoided for long-term fasting birds that are close to or below the critical body mass (e.g., in birds at the end of molt or after an especially long breeding shift).

Nonetheless, both our prediction equations yielded reasonable estimates of $M_{\mathrm{b}}$, as suggested by the low error (ca. 6\%) on body mass we obtained when predicting it from $G_{\mathrm{b}}$ regardless of the method used: that is, using a jackknife approach in the same individuals (whether or not we excluded birds at the end of molt) or predicting $M_{\mathrm{b}}$ from $G_{\mathrm{b}}$ in a test group. This error is actually lower than that reported by Halsey et al. (2008), some $9 \%$, who used a combination of structural size measurements (bill, flipper, and tarsus) to predict the critical $M_{\mathrm{b}}$ of king penguins, although the authors had a lower sample size at hand. Body girth thus provided a dynamic surrogate measure of $M_{\mathrm{b}}$ over an extensive range of situations (interquartile values of body mass ranging from 8.6 to $13.4 \mathrm{~kg}$ in molting and breeding birds) and could be used instead of $M_{\mathrm{b}}$ and in combination with structural size to establish a condition index in penguins. This was confirmed by the fact that we found very good correlations $\left(r_{\mathrm{s}}=0.92\right)$ when establishing condition indexes from either $M_{\mathrm{b}}$ or $G_{\mathrm{b}}$, that is, residuals from OLS regressions of either $M_{\mathrm{b}}$ or $G_{\mathrm{b}}$ on structural size (Schulte-Hostedde et al. 2005). Further, our results show that $G_{\mathrm{b}}$ was a consistent predictor of $M_{\mathrm{b}}$ within individuals, as suggested by the significant relationship we obtained between changes in $M_{\mathrm{b}}$ and changes in $G_{\mathrm{b}}$ within the same birds. Indeed, $\delta G_{\mathrm{b}}$ was significantly associated with $\delta M_{\mathrm{b}}$, although the mean percentage error of $\delta M_{\mathrm{b}}$ predictions from $\delta G_{\mathrm{b}}$ using a jackknife approach was much higher (i.e., $36.3 \% \pm 8.9 \%$ ). We found that a $1-\mathrm{cm}$ change in body girth corresponded to a change in body mass of approximately $207 \mathrm{~g}$. Given that, while on land, king penguins are for the most part in phase 2 of fasting and lose approximately 160-190 g/d (e.g., Cherel et al. 1988; Groscolas et al. 2010), it follows that estimates of $M_{\mathrm{b}}$ based on $G_{\mathrm{b}}$ should be made at least 2-3 d apart so that $G_{\mathrm{b}}$ differs by at least $1 \mathrm{~cm}$ between two successive measurements.

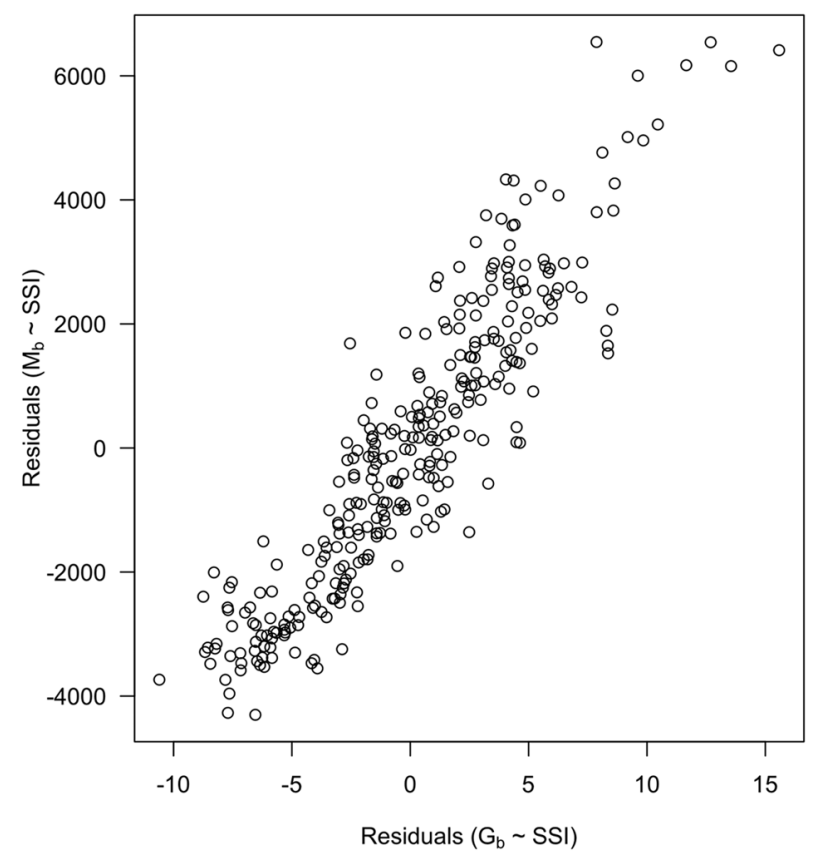

Figure 4. Relationship between the residuals of a regression of body mass $\left(M_{\mathrm{b}}\right)$ or body girth $\left(G_{\mathrm{b}}\right)$ on an index of structural size (SSI) in king penguins. The SSI was the first component of a principal component analysis (see "Methods"). 


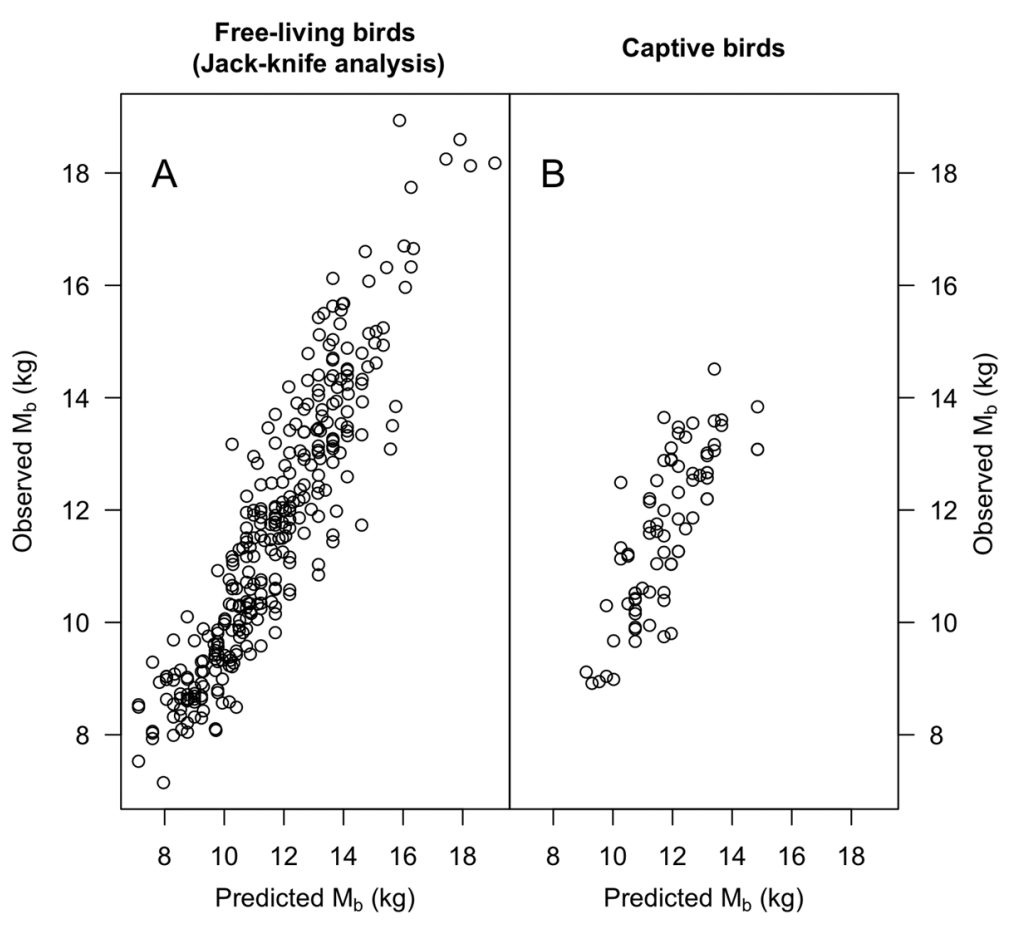

Figure 5. Observed body mass $\left(M_{\mathrm{b}}\right)$ versus predicted $M_{\mathrm{b}}$ from body girth $\left(G_{\mathrm{b}}\right)$ in king penguins. $A$, Predicted values $(n=305)$ were obtained from the 234 free-living birds from which the predicting equation $\left(\mathrm{eq}_{\mathrm{bred}}\right.$ or $\mathrm{eq}_{\text {molt }}$, used as appropriate) was derived, using a jackknife approach (see Halsey et al. 2008 and "Methods"). B, Predicted values $(n=79)$ were obtained from 10 captive individuals measured several times (six to nine measurements per bird) during prolonged fasting and using $\mathrm{eq}_{\mathrm{breed}}$.

In conclusion, the method reported in this study provides researchers with an easily measurable surrogate of $M_{\mathrm{b}}$, and our results suggest that $G_{\mathrm{b}}$ may be used instead of $M_{\mathrm{b}}$ along with structural size measurements to derive robust body condition indexes over a range of situations in king penguins. We suggest two different equations for estimating $M_{\mathrm{b}}$ from $G_{\mathrm{b}}$ in molting and breeding king penguins, which should not be sensitive to experimenters, provided that $G_{\mathrm{b}}$ measurements are taken at the armpit, beneath the flippers, and with birds in a standardized upright position. Changes in $G_{\mathrm{b}}$ may also be a useful and dynamic measure for studying changes in $M_{\mathrm{b}}$, although care should be taken as to the time needed between two consecutive measures of $G_{\mathrm{b}}$ to detect relevant changes in $M_{\mathrm{b}}$ and one should be cautious about the errors associated with such predictions. Using body girth to establish body condition is likely to be of interest in other penguins and large seabird species as well and remains to be tested.

\section{Acknowledgments}

This research was supported by the French Polar Institute (Institut Paul Emile Victor) as part of research project 119 and by the Centre National de la Recherche Scientifique (CNRSINEE). Two anonymous reviewers provided insightful comments on the study. Logistical support was provided by Terres
Australes et Antarctiques Françaises. V.A.V. was the recipient of a postdoctoral fellowship from the Fyssen Foundation.

\section{Literature Cited}

Atkinson S.N. and M.A. Ramsay. 1995. The effects of prolonged fasting on the body composition and reproductive success of female polar bears (Ursus maritimus). Funct Ecol 9:559567.

Balbontín J., A.P. Møller, I.G. Hermosell, A. Marzal, M. Reviriego, and F. De Lope. 2012. Lifetime individual plasticity in body condition of a migratory bird. Biol J Linn Soc 105: 420-434.

Boggs C.L. 1992. Resource allocation: exploring connections between foraging and life history. Funct Ecol 6:508-518.

Brown M.E. 1996. Assessing body condition in birds. Pp. 67135 in V. Nolan and E.D. Ketterson, eds. Current ornithology. Vol. 13. Plenum, New York.

Chastel O., H. Weimerskirch, and P. Jouventin. 1995. Influence of body condition on reproductive decision and reproductive success in the blue petrel. Auk 112:964-972.

Cherel Y., J.-B. Charrassin, and E. Challet. 1994a. Energy and protein requirements for molt in the king penguin Aptenodytes pataconicus. Am J Physiol 35:R1182-R1188.

Cherel Y., J. Gilles, Y. Handrich, and Y. Le Maho. 1994b. Nutrient reserve dynamics and energetics during long-term fast- 
ing in the king penguin (Aptenodytes patagonicus). J Zool (Lond) 234:1-12.

Cherel Y., J.-P. Robin, and Y. Le Maho. 1988. Physiology and biochemistry of long-term fasting in birds. Can J Zool 66: 159-166.

Christe P., A.P. Møller, and F. de Lope. 1998. Immunocompetence and nestling survival in the house martin: the tasty chick hypothesis. Oikos 83:175-179.

Côté S.D. 2000. Aggressiveness in king penguins in relation to reproductive status and territory location. Anim Behav 59: 813-821.

Dobson F.S. and G.R. Michener. 1995. Maternal traits and reproduction in Richardson's ground squirrels. Ecology 76: 851-862.

Dobson F.S., T.S. Risch, and J.O. Murie. 1999. Increasing returns in the life history of Columbian ground squirrels. J Anim Ecol 68:73-86.

Fahlman A., L.G. Halsey, P.J. Butler, D.R. Jones, A. Schmidt, S. Durand, G. Froget, et al. 2006. Accounting for body condition improves allometric estimates of resting metabolic rates in fasting king penguin, Aptenodytes patagonicus. Polar Biol 29:609-614.

Gauthier-Clerc M., Y. Le Maho, J.-P. Gendner, J. Durant, and Y. Handrich. 2001. State-dependent decisions in long-term fasting king penguins, Aptenodytes patagonicus. Anim Behav 62:661-669.

Green A.J. 2001. Mass/length residuals: measures of body condition or generators of spurious results? Ecology 82:14731483.

Griffiths R., M.C. Double, K. Orr, and R.J.G Dawson. 1998. A DNA test to sex most birds. Mol Ecol 7:1071-1075.

Groscolas R. 1978. Study of molt fasting followed by an experimental forced fasting in the emperor penguin, Aptenodytes forsteri: relationship between feather growth, body weight loss, body temperature and plasma fuel levels. Comp Biochem Physiol A 61:287-295.

- 1990. Metabolic adaptations to fasting in emperor and king penguins. Pp. 269-296 in L.S. Davis and J.T. Darby, eds. Penguin biology. Academic Press, San Diego, CA.

Groscolas R. and Y. Cherel. 1991. How to molt while fasting in the cold: the metabolic and hormonal adaptations of emperor and king penguins. Ornis Scand 23:328-334.

Groscolas R. and J.-P. Robin. 2001. Long-term fasting and refeeding in penguins. Comp Biochem Physiol A 128:645-655.

Groscolas R., V. Viera, N. Guerin, Y. Handrich, and S.D. Côté. 2010. Heart rate as a predictor of energy expenditure in undisturbed fasting and incubating penguins. J Exp Biol 213: 153-160.

Halsey L.G., M. Le Coadic, and Y. Handrich. 2008. Estimating the critical body mass of king penguins. Polar Biol 31:395398.

Jakob E.M., S.D. Marshall, and G.W. Uetz. 1996. Estimating fitness: a comparison of body condition indices. Oikos 77: 61-67.

Kato A., Y. Ropert-Coudert, and A. Chiaradia. 2008. Regulation of trip duration by an inshore forager, the little penguin (Eudyptula minor), during incubation. Auk 125:588-593.

Kokko H., M.P. Harris, and S. Wanless. 2004. Competition for breeding sites and site-dependent population regulation in a highly colonial seabird, the common guillemot Uria aalge. J Anim Ecol 73:367-376.

Lindén M., L. Gustafsson, and T. Pärt. 1992. Selection on fledging mass in the collared flycatcher and the great tit. Ecology 73:336-343.

Madsen T. and R. Shine. 1999. The adjustment of reproductive threshold to prey abundance in a capital breeder. J Anim Ecol 68:571-580.

Merila J. and D.A. Wiggins. 1995. Offspring number and quality in the blue tit: a quantitative genetic approach. J Zool (Lond) 237:615-623.

Muggeo V.M.R. 2003. Estimating regression models with unknown break-points. Stat Med 22:3055-3071.

- 2008. Segmented: an R package to fit regression models with broken-line relationships. R News 8:20-25, http:// cran.r-project.org/doc/Rnews/.

Piersma T. 1984. Estimating energy reserves of great crested grebes Podiceps crista on the basis of body dimensions. Ardea 72:119-126.

Pinheiro J., D. Bates, S. DebRoy, D. Sarkar, and the R Development Core Team. 2011. nlme: linear and nonlinear mixed effects models. R package version 3.1-102. R Foundation for Statistical Computing, Vienna.

Potti J. 1993. Environmental, ontogenetic, and genetic variation in egg size of pied flycatchers. Can J Zool 71:1534-1542.

R Development Core Team. 2011. R: a language and environment for statistical computing. R Foundation for Statistical Computing, Vienna.

Saraux C., V.A. Viblanc, N. Hanuise, Y. Le Maho, and C. Le Bohec. 2011. Effects of individual pre-fledging traits and environmental conditions on return patterns in juvenile king penguins. PLoS ONE 6:e20407.

Schulte-Hostedde A.I., J.S. Millar, and G.J. Hickling. 2001. Evaluating body condition in small mammals. Can J Zool 79: 1021-1029.

Schulte-Hostedde A.I., B. Zinner, J.S. Millar, and G.J. Hickling. 2005. Restitution of mass-size residuals: validating body condition indices. Ecology 86:155-163.

Stonehouse B. 1960. The king penguin Aptenodytes patagonica of South Georgia. Sci Rep Falkl Isl Depend Surv 23:1-81.

Weimerskirch H., J.C. Stahl, and P. Jouventin. 1992. The breeding biology and population dynamics of king penguin Aptenodytes patagonica on the Crozet Islands. Ibis 134:107-117. Williams T.D. 1995. The penguins. C.M. Perrins, W.J. Bock, and J. Kikkawa, eds. Oxford University Press, New York. 